This is the peer reviewed accepted manuscript of:

Cinausero M, Rihawi K, Cortiula F, Follador A, Fasola G, Ardizzoni A. Emerging therapies in malignant pleural mesothelioma.

Crit Rev Oncol Hematol. 2019 Dec;144:102815.

Final version available at: https://doi.org/10.1016/j.critrevonc.2019.102815

Rights / License:

The terms and conditions for the reuse of this version of the manuscript are specified in the publishing policy. For all terms of use and more information see the publisher's website.

This item was downloaded from IRIS Università di Bologna (https://cris.unibo.it/)

When citing, please refer to the published version. 


\section{Emerging therapies in Malignant Pleural Mesothelioma}

Marika Cinausero ${ }^{\mathrm{a}, \mathrm{b}, *}$, Karim Rihawi ${ }^{\mathrm{a}, \mathrm{c}}$, Francesco Cortiula ${ }^{\mathrm{a}, \mathrm{b}}$, Alessandro Follador ${ }^{\mathrm{a}}$, Gianpiero Fasola ${ }^{a}$, Andrea Ardizzoni ${ }^{d}$

a Department of Oncology, University Hospital of Udine, Italy

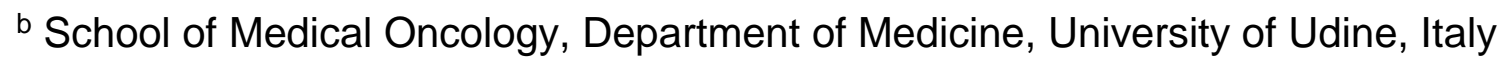

${ }^{\mathrm{C}}$ Department of Experimental, Diagnostic and Specialty Medicine - DIMES, University of Bologna, Italy

d Department of Oncology, Policlinico S. Orsola-Malpighi, University of Bologna, Bologna, Italy

* Corresponding author at: Marika Cinausero, Department of Oncology, University Hospital of Udine, S. Maria della Misericordia 15, 33100 Udine (UD), Italy.

E-mail address: marika.cinausero@gmail.com

\section{Graphical abstract}




\section{Mesothelioma Cancer Cell}

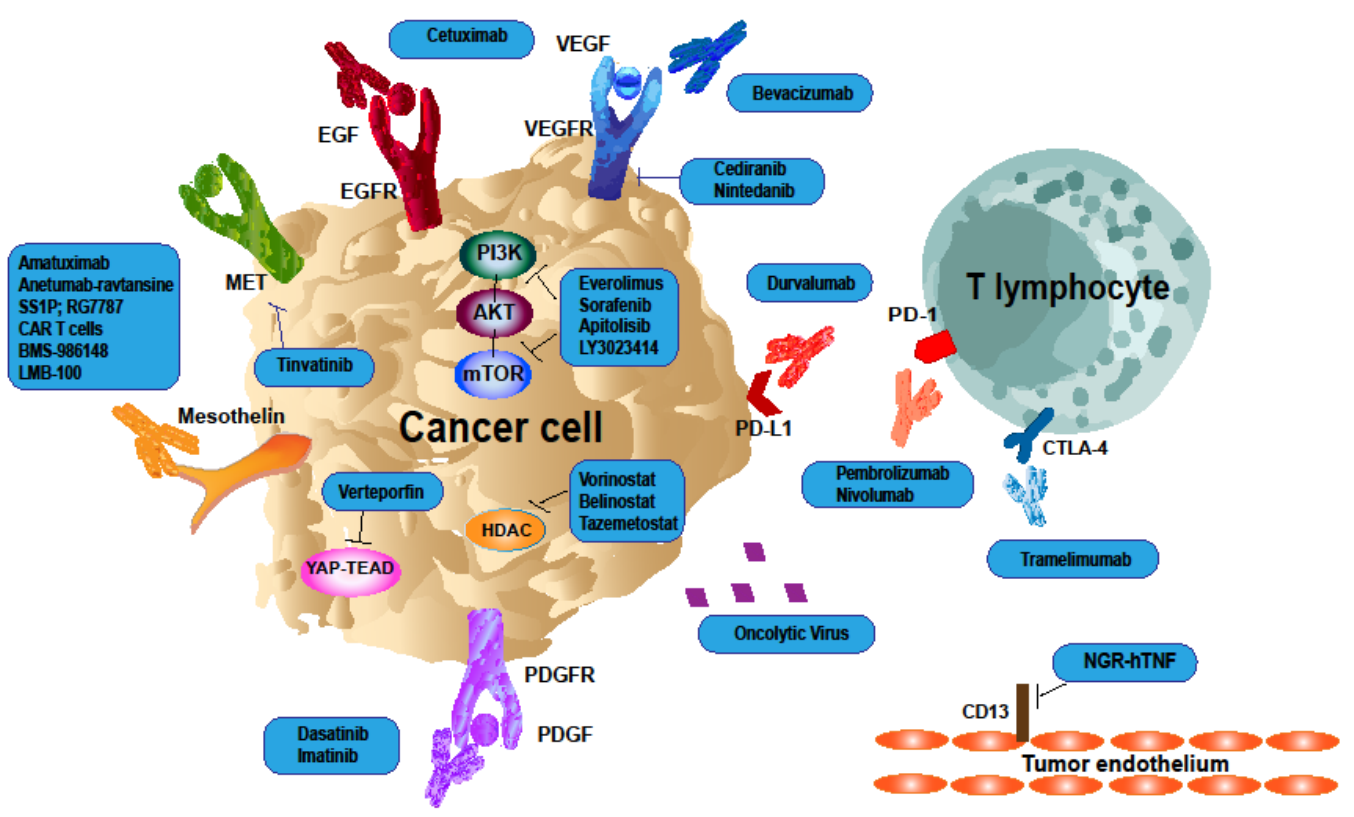

\section{Highlights}

- Malignant pleural mesothelioma is a rare cancer characterized by poor prognosis

- The management of malignant pleural mesothelioma is still a critical challenge

- To date, systemic CT represents the treatment backbone for unresectable disease

- Novel therapeutic approaches are under investigation to improve patients' outcome

- Immunotherapy represents one of the most promising emerging treatment strategies

\section{Abstract}


Malignant pleural mesothelioma (MPM) is a rare cancer of the pleural surfaces frequently related to asbestos exposure. It is characterized by a poor prognosis even for patients treated with trimodality therapy, including surgery, chemotherapy and radiotherapy. Moreover, the majority of patients are not candidates for surgery due to disease advanced stage or medical comorbidities. For these patients, the survival rate is even lower and few therapeutic options are currently available. Nevertheless, many interesting novel approaches are under investigation, among which immunotherapy represents one of the most promising emerging strategies. In this review, we will discuss the role of new therapeutic options, particularly immunotherapy, and present the results of the most important and promising clinical trials.

Keywords: malignant pleural mesothelioma, immunotherapy, target therapy, molecular, anti-mesothelin therapy, antiangiogenic therapy

\section{Introduction}

Malignant pleural mesothelioma (MPM) is a rare cancer of the pleura. Its most frequent cause is asbestos exposure, being responsible for about $80 \%$ of diagnosis [1]. The 
majority of patients with MPM, with the exception of those with resectable disease and eligible to multimodality therapy, have a poor prognosis, with a medium survival ranging from 12 to 18 months after diagnosis [2]. Morever, survival is usually worse for male patients compared to women [3].

Worldwide MPM incidence is probably underestimated but is unequivocally rising in both developed and developing countries, and will likely peak around 2025 [4].

Pleural primary site, poor ECOG performance status, high serum levels of platelets and LDH, advanced age and non-epithelial histology are independent negative prognostic and predictive factors $[5,6]$.

Symptoms, typically dyspnea, cough and chest pain, usually occur in a late-stage disease. Typical radiology signs of MPM are pleural thickening, nodules and effusion. Patients history of asbestos exposure is mandatory to collect. Diagnosis needs to be confirmed with pleural biopsy or cytological specimen $[3,6]$.

Therapeutic options for MPM include surgery, radiotherapy (RT) and chemotherapy (CT), which may be combined in a multimodality treatment.

Of note, only $20 \%$ of MPM patients are eligible for radical surgery to remove macroscopic disease (R0 or $\mathrm{R} 1$ resection) with a 5-years survival rate less than $15 \%$. For patients not suitable for radical surgery, systemic CT represents the treatment backbone $[7,8]$.

Despite the revolutionary advancements seen in the last decade in the treatment of many tumor types, the MPM prognosis has remained substantially the same. Novel targets and treatments are under investigation and strongly needed to improve patients' outcome and raise the bar in MPM treatment.

\subsection{Pathobiology}


The main cause of MPM is occupational or para-occupational asbestos exposure and the disease generally occurs after a long latency period ranging from 20 to 70 years. As a matter of fact, the incidence is increasing despite the ban on asbestos use in most countries since the 1980s. Moreover, asbestos is still being used in some developing countries. Minerals such as erionite have also been implicated in the development of MPM. Other causes of mesothelioma include irradiation of chest wall or mediastinum and simian virus 40 [1].

However, about $20 \%$ of patients who develop MPM do not have aby history of previous exposure to asbestos or to any other known risk factor, suggesting that genetic predisposition may also be involved in MPM pathogenesis [4].

In recent years, a better understanding of mesothelioma pathobiology has led to an improved knowledge of its genetics and epigenetics as well as tumor microenvironment and immunobiology.

p53 and p16/p14 genes are frequently inactivated in MPM, leading to inactivation of tumor-suppressing pathways $[9,10]$.

Nasu et al have identified somatic mutations in the BRCA-associated protein 1 (BAP1) suppressor gene in $57-63 \%$ of cases. Moreover, germline mutations of this gene predispose to the development of MPM and various other malignancies [4,11]. Additionally, genomic analysis of mesothelioma has also revealed other mutations, gene fusions or splicing alterations involved in MPM pathogenesis $[12,13]$. The genetic mutation of the neurofibromatosis type 2 (NF2) suppressor gene has been identified in up to $40 \%$ of MPM cases. This gene encodes a protein named Merlin, which is one of the crucial elements of the Hippo pathway regulating the invasiveness, proliferation and survival of MPM cells [10]. 
Inactivation of large tumor suppressor homolog 2 (LATS2) and 1 (LATS1) has also been found in MPM. Furthermore, the overexpression of focal adhesion kinase (FAK) and the presence of subpopulations of cancer stem cells conferring resistance to chemotherapy (CT) has been identified in preclinical models [12]. Targeting such pathways remains a crucial area of active research. Further details on mesothelioma pathobiology will be discussed in treatment-addressed sections of this review.

\subsection{Treatment of resectable malignant pleural mesothelioma}

\subsubsection{Surgery}

Univocal consensus regarding the role of surgery in MPM has not yet been reached. Both extrapleural pneumonectomy (EPP) and lung sparing procedures such as pleurectomy/decortication (P/D) failed in demonstrating a clear survival advantage in phase III clinical trials. Moreover, both procedures are associated with not negligible morbidity and mortality and clinical trials comparing EPP with P/D are lacking. Better outcomes are guaranteed in high-volume centers with adequate expertise [14]. To date, no clear prognostic factors have been identified to predict which patients will rapidly recover and benefit from surgery. However, Cao et al identified non-epithelial histology and N2 nodal involvement as predictive factors of poor outcome after EPP, suggesting that patients with similar characteristics should not be directed to this type of surgery [15].

A retrospective review of 663 U.S. patients who underwent surgery, showed a worse overall survival (OS) and a greater mortality with EPP compared to P/D [16]. Moreover, a recent systematic review of the literature conducted by Cao et al suggests lower morbidity ( $62 \%$ vs $28 \%, p<0.0001)$ and mortality $(6.8 \%$ vs $2.9 \%, p=0.02)$ and similar survival benefit (13-29 months vs 12-22 months) with P/D compared to EPP [17]. 


\subsubsection{Multimodality treatment}

Radiotherapy plays a key role in palliative setting, local prophylactic irradiation of surgical port sites and in radical treatment. The introduction of intensity modulated RT (IMRT) over the last decade improved efficacy with less toxicity [3]. This approach was initially evaluated after EPP [18] and then expanded to preoperative setting [19] and to IMRT approach after P/D [20]. The SMART trial showed that neoadjuvant IMRT followed by EPP seems to be safe and feasible, particularly in patients with epithelioid tumors [19].

Radical surgery with neoadjuvant RT can achieve a local control of the disease, but distant metastases will develop in most patients. Thus, the efficacy of induction CT regimen, followed by surgery and subsequent $R T$ have been evaluated in several nonrandomized studies and a median OS ranging from 14 to 25.5 months was found for this approach $[4,21]$. However, we should take into account the high patients selection in these trials [21].

In the trimodality therapy setting non-EPP surgeries have demonstrated better outcomes, in terms of both quality of live and survival [22]. Carefully selected patients may benefit from multimodality approach but adequately powered randomized trials are required in order to establish the optimal strategy for the integration of CT and RT with surgery.

\subsection{Treatment of unresectable malignant pleural mesothelioma}

CT represents the standard treatment for unresectable MPM in patients with ECOG performance status 0-2 [8]. 
Single-agent CT has achieved modest results with a response rate up to $20 \%[3,23]$. Compared to best supportive care (BSC), both single agent vinorelbine and cisplatin, vinblastine and mitomycin regimen failed to demonstrate a statistically significant survival benefit [24].

The phase III EMPHACIS trial by Vogelzang et al led to the FDA approval of first-line cisplatin plus pemetrexed chemotherapy, demonstrating a significant survival advantage for this regimen compared to single agent cisplatin, with a median OS of 12.1 months compared to 9.7 months in the control arm [7]. The addition of folic acid and vitamin B12 to CT further improved the outcome while reducing toxicities.

A similar trial compared cisplatin $80 \mathrm{mg} / \mathrm{mq}$ plus the antimetabolite raltitrexed to cisplatin alone [25], showing an improvement of both OS and PFS, comparable to the pemetrexed study. Taking into consideration economic aspects, toxicity profiles and clinical experience, the usually recommended first line regimen is represented by cisplatin plus pemetrexed. Carboplatin plus pemetrexed is a reasonable alternative to prevent toxicities in frail patients, even though the evidence of its efficacy is based on phase II studies [26-30].

Cisplatin plus gemcitabine regimen has been evaluated in phase II trials and represents a valid alternative when pemetrexed is controindicated [3,31]. Also carboplatin with gemcitabine has shown a $26 \%$ response rate with a good tolerance [32]. To our knowledge, no randomized clinical trial has compared cisplatin plus pemetrexed to cisplatin plus gemcitabine. Conversely, the combination of cisplatin and anthracyclines showed no advantage compared with standard regimens in phase II trials $[33,34]$. 
A phase II trial evaluated the activity of carboplatin-pemetrexed plus bevacizumab as first-line therapy on 77 MPM patients. The primary endpoint (improvement of median PFS from 6 to 9 month compared to standard CT) was not reached [35].

However, the multicenter randomized phase III MAPS trial comparing cisplatinpemetrexed to cisplatin-pemetrexed plus bevacizumab [36], showed a benefit of about 2 months in both PFS and OS, despite an increased toxicity (grade 3 hypertension, thrombotic events, proteinuria). Based on these results, this triplet represents an option in selected patients.

Notably, according to MED trial first-line CT should be started at diagnosis, even in asymptomatic patients, without a detrimental effect of immediate treatment [37].

Few data are available about second line therapy. Manegold et al conducted a retrospective analysis to identify potential predictors of survival in MPM patients receiving second-line CT in the setting of EMPHACIS trial [38]. The authors reported a longer survival in patients who received post-study CT (42\% of patients) compared with those not receiving second-line therapy. However, some factors (good performance status, early stage, epithelial histology, younger age) characterizing patients treated with second-line CT could have influenced the outcome.

Single agent pemetrexed showed PFS improvement compared to BSC (3.6 vs 1.5 months) in pemetrexed-naïve patients. [39].

Moreover, phase II trials demonstrated improved response rates for gemcitabine, vinorelbine or anthracyclines compared to BSC [40-43]. Cisplatin-gemcitabine [44], irinotecan-cisplatin-mitomycin [45], and oxaliplatin-raltitrexed [46,47], have also been investigated as second-line treatment, but prospective trials are lacking.

The role of pemetrexed as maintenance treatment is under investigation [48]. 
Moreover, rechallenge with pemetrexed plus platinum-based CT could be considered in patients who have obtained a clinical benefit from first-line CT, as suggested by the clinical trial conducted by Ceresoli et al [49].

To date, the American Society of Clinical Oncology guidelines and European Society of Medical Oncology guidelines recommend vinorelbine as second-line therapy particularly in patients for whom clinical trials are not an option.

\section{New frontiers in the treatment of MPM patients}

Several approaches have been studied or are currently under evaluation in an effort to improve systemic treatment for MPM and to identify predictive biomarkers [50].

\subsection{Antiangiogenic therapy}

Angiogenesis represents a key-factor for tumor growth and progression. In addition to the positive results of bevacizumab in the MAPS trial [36], several anti-angiogenic small molecules have been investigated.

A randomized phase III trial evaluated thalidomide as maintenance therapy after firstline platinum plus pemetrexed-based CT; however, no improvement in TTP was reported in patients receiving thalidomide compared with those in the BSC arm [51]. Conversely, Grosso et al reported the results of a phase II trial evaluating the combination of cisplatin-pemetrexed plus nintedanib versus cisplatin-pemetrexed alone [52]. The authors showed a trend towards improved OS and a statistically significant longer PFS in patients receiving nintedanib ( $\mathrm{HR} \mathrm{0.54;95 \%} \mathrm{Cl} 0.33-0.87$ ). Unfortunately, the results of the phase III part of LUME-Meso trial did not meet its primary (PFS) and key secondary endpoints. Thus, the use of first-line nintedanib in 
combination with cisplatin-pemetrexed for patients with epithelioid MPM is not currently supported [53].

In two phase II trials, the tyrosine kinase inhibitor ( $\mathrm{TKI}$ ) cediranib as second-line treatment demonstrated an ORR of approximately $10 \%[54,55]$. Moreover, a phase I study was performed to evaluate the addition of cediranib to standard first-line CT followed by cediranib as maintenance therapy; a median PFS and OS of 13 and 16 months, respectively, was reported [56]. The phase II study SWOG S0905, whose results were presented at the 2018 ASCO meeting, confirmed the potential role of cediranib in the same setting: PFS was significantly prolonged in the cediranib arm, compared to placebo (HR 0.69, p = 0.096, median PFS 7.2 vs 5.6 months) [57].

The TKIs sunitinib and vatalanib demonstrated negligible response rates in phase II studies [58,59]. Sorafenib showed a response rate of $6 \%$ in MPM chemo naïve or pretreated patients [60]; moreover, another phase II trial showed a response rate of $36 \%$ in platinum-based CT pretreated patients [61].

In preclinical models, the combination of sorafenib and everolimus has proven to be effective against mammalian target of rapamycin (mTOR) and ERM pathways in tumor cells, suggesting targeted combination therapy as a promising approach against MPM [62]. Preclinical data also showed promising results with the combination of pemetrexed with the c-MET and tubulin inhibitor tivantinib in MPM cell lines; the authors demonstrated synergistic activity between the two agents resulting in inhibition of tumor growth and cell migration [63]. NCT02049060 is ongoing to evaluate the combination of tivantinib plus carboplatin and pemetrexed [64].

Moreover, a randomized, placebo-controlled, phase III trial evaluated the experimental antiangiogenic agent NGR-hTNF addition to a standard single agent second line therapy. Notwithstanding preliminary results showed a median PFS of 3.4 vs 1.9 
months [65], but the primary endpoint OS did not differ between the two treatment cohorts (HR 0.94, 95\% C.I. 0.75-1.18; $p=0.58$ ) [66].

\subsection{Anti-mesothelin therapeutic strategies}

Mesothelin is highly expressed in mesothelioma cancer cells (95\% of epithelioid MPM). Thus, the immune-targeting of mesothelin through immunotoxins, antibodies, vaccines and chimeric-antigen receptor T-cells is under evaluation in several phase $\mathrm{I} / \mathrm{I}$ trials and could be an effective strategy $[67,68]$.

The monoclonal antibody amatuximab has been evaluated in different phase I trials showing no response rate $[69,70]$. In a phase II study, the combination of this agent with standard first-line CT showed response rate or stable disease rate of $90 \%$, and median OS of 14.8 months, despite no improvement in PFS [71]. A double-blind, randomized, phase II trial evaluating the addition of amatuximab to CT has completed recruitment [72]. Antibody-drug conjugates targeting mesothelin have also been investigated in mesothelioma patients. Anetumab ravtansine consists of a human antimesothelin antibody conjugated to the maytansinoid tubulin inhibitor DM4. Blumenschein et al conducted a phase I trial demonstrating a durable $75 \%$ disease control rate in MPM patients treated with this agent [73]. Furthermore, NCT02639091 phase I trial is ongoing to evaluate the combination of anetumab ravtansine with cisplatin-pemetrexed in mesothelin-expressing solid tumors [74].

Another anti-mesothelin antibody conjugated to cytotoxic drug is represented by BMS986148, currently under investigation in NCT02341625 trial [75].

A phase I trial assessing the mesothelin targeted immunotoxin LMB-100 in MPM patients is ongoing [76]. Other agents targeting mesothelin have showed preliminary 
efficacy against mesothelioma in clinical trials, such as recombinant immunotoxins SS1P and RG7787 [50,77].

\subsection{EGFR inhibition and microRNA technology}

The expression of epidermal growth factor receptor (EGFR) in mesothelioma cancer cells is reported to range from 32 to $97 \%$ [3]. However, few data are available regarding the inhibition of EGFR through small molecules or monoclonal antibodies in MPM patients. Erlotinib failed to demonstrate activity in a phase II study on 63 mesothelioma patients, with $75 \%$ overexpressing EGFR [78]. Similarly, single-agent gefitinib did not achieve valid response rates [79]. Recently, the clinical trial NCT00996567, evaluating the first-line combination of cetuximab plus platinum-pemetrexed, has completed recruitment [80].

MicroRNA (miRNA) mimics are small, double-stranded RNA innovative molecules designed to mimic endogenous RNA molecules and useful for gene targeting and silencing approaches. The expression of the miR-15 and miR-16 family miRNAs has been shown to be reduced in MPM tumor specimens, leading to uncontrolled tumor growth. Conversely, the use of miRNA mimics restoring miR-15/16 expression demonstrated to inhibit tumor growth in MPM cell lines [81].

Van Zandwijk et al conducted a first-in-human, open-label, phase 1 study to investigate the safety profile, dosing, and activity of minicells loaded with miR-16-based mimic miRNA, delivering cargos of miR-16 to EGFR-expressing cells (TargomiRs) [82]. The trial showed an acceptable safety profile and signs of activity, further studies are awaited. 


\subsection{PDGFR inhibition}

Mesothelioma cancer cells express both PDGF and PDGFR- $\alpha / \beta$ [3]. Thus, several TKIs targeting PDGFR pathway have been studied. Imatinib, currently approved for the treatment of myeloid leukemia and gastrointestinal stromal tumors, demonstrated activity in preclinical models through the induction of apoptosis. However, negative results have been observed in phase I and phase II trials, and none of the mesothelioma patients receiving different doses of single-agent imatinib had a response $[3,83]$.

Notably, preclinical studies showed synergistic effect between imatinib and CT. Tsao et al conducted a phase I trial to evaluate the combination of imatinib and cisplatinpemetrexed regimen, showing clinical benefit in some patients but poor tolerance to the treatment [84]. Another phase I trial showed antitumor activity and manageable toxicity with imatinib plus gemcitabine in the setting of refractory solid tumors; 1 MPM patient out of 5 had a partial response [85]. The phase II NCT02303899 trial, evaluating the combination of imatinib and gemcitabine in pretreated patients has currently terminated the enrollment [86].

The TKI dasatinib failed in demonstrating activity in a phase II trial on pretreated MPM patients [87]. However, preclinical studies suggest that this agent can modulate sensitivity of cancer cells to pemetrexed through the down-regulation of thymidylate synthase [88].

\subsection{Inhibition of PI3K/AKT/mTOR signaling}

The cellular pathway involving phosphatidylinositol-4,5-biphosphate 3-kinases (PI3K), mTOR and AKT is crucial in promoting tumor proliferation, growth, differentiation, and tumor motility. Its alterations have been identified also in mesothelioma cancer cells, 
leading to the hypothesis that targeting this pathway could provide clinical benefit in MPM patients [3].

Monotherapy with the mTOR inhibitor everolimus showed limited activity in a phase II trial, with an ORR of $0-10 \%$ [89].

As previously mentioned, preclinical models suggested that the combination of sorafenib and everolimus could be effective in MPM cancer cells [62].

In preclinical models, the PI3K-mTOR dual inhibitor LY3023414 have demonstrated to have antitumor activity against skin squamous cell carcinoma [90], esophageal adenocarcinoma [91] and colorectal cancer with APC and PI3K mutations [92]. The first-in-human phase I NCT01655225 trial is currently recruiting to study this agent [93]. The small molecule apitolisib is a mTOR-PI3K inhibitor which showed modest but durable antitumor activity in the first-in-human phase I study on 120 patients with solid tumors, including 33 MPM patients [94].

Furthermore, inhibition of PI3K and MET pathways has demonstrated to be effective in reducing cell proliferation, motility and survival in in-vitro studies [95].

\subsection{Histone deacetylase inhibitors}

The identification of BAP1 mutations in MPM has led to investigate the role of histone deacetylase inhibitors in mesothelioma patients.

The phase III trial on 661 pretreated patients randomly assigned to vorinostat or placebo did not demonstrate a clinically meaningful benefit. Indeed, the authors reported a not clinically significant increase in PFS with vorinostat compared with placebo (6.3 vs 6.1 weeks, HR $0.75,95 \% \mathrm{Cl} 0.63-0-88$ ) with a not statistically significant difference in OS (30.7 vs 27.1 weeks, $\mathrm{HR} 0.98,95 \% \mathrm{Cl} 0.83-1.17$ ) [96]. Similarly, belinostat failed to demonstrate benefit in a phase II trial on recurrent MPM [97]., In a 
phase II study, presented at ASCO 2018 meeting, tazemetostat showed promising activity in patients with relapsed or refractory MPM with BAP1 loss of function. 31 pts (51\%) achieved disease control at 12 weeks and 15 patients (25\%) sustained disease control at 24 weeks. No patients discontinued treatment due to adverse events [98].

\subsection{FAK inhibition}

The loss of expression of the gene suppressor NF2 has been identified in $40-50 \%$ of mesothelioma samples. This gene encodes for a protein (Merlin) that inhibits FAK, an intracellular molecule involved in the intracellular adhesion. Consequently, loss of NF2 leads to altered migration and invasiveness of tumor cells [3].

The small molecule Defactinib is a FAK inhibitor which has demonstrated antitumor activity as maintenance therapy after platinum-pemetrexed CT in preclinical models [99]. A phase I study conducted in 9 Asian patients with solid tumors demonstrated good tolerance of defactinib and a durable stable disease of 24 weeks in 2 out of 9 patients (1 with MPM) [100]. The multinational randomized phase II COMMAND trial failed to demonstrate the effectiveness of maintenance therapy with defactinib compared to placebo in MPM patients not progressed on firs-line standard CT. Indeed, no benefit on patients' outcome was shown in an interim analysis and the trial stopped enrollment early $[50,101]$.

A phase I-II trial is currently recruiting to evaluate the combination of Defactinib with Pembrolizumab in various neoplasms, including mesothelioma [102].

Another FAK inhibitor, GSK2256098, showed an acceptable safety profile and clinical activity in MPM patients, particularly those with loss of Merlin (PFS 23.4 weeks, $n=14$ ) compared with Merlin positive patients (11.4 weeks, $n=9$ ) [103]. 


\subsection{Other targeted therapeutic approaches}

The Hippo pathway plays a critical role in cell proliferation and survival, and has proven to be dysregulated in MPM through alterations of Hippo genes such as NF2, LATS2, LATS1, and MST1 [12]. In $70 \%$ of MPM cases, this dysregulation leads to a constitutively activation of the transcription factor Yes-associated protein (YAP), which then promotes proliferative signaling $[12,104]$. Verteporfin, a photosensitizer agent used in the treatment of neovascular macular degeneration, was found to significantly downregulate transcription in MPM tissue, leading to YAP reduction and suggesting the potential role of YAP as a therapeutic target in mesothelioma [105].

HSP90 inhibitors, such as ganetespib, are also under investigation combined with firstline standard CT in MPM patients [106].

O'Brien et al performed a single arm phase II trial to evaluate a first-line combination of cisplatin plus bortezomib, a proteasome inhibitor used in multiple myeloma patients. However, the authors showed a PFS rate at 18 weeks of $53 \%$, which did not meet the criteria for activity to predict success in a phase III trial [107].

Additionally, it was demonstrated that $60 \%$ of MPM patients do not express argininosuccinate synthetase 1 (ASS1), resulting in arginine depletion. Szlosarek et al conducted a phase 2 randomized clinical trial evaluating the addition of pegylated arginine deaminase (Adi-PEG20) to BSC in mesothelioma ASS1 negative patients. They reported an improvement of the primary endpoint PFS in the Adi-PEG20 group compared with patients receiving only BSC (mPFS 3.2 vs 2 months, HR $0.56, p=0.03$ ). Moreover, a phase 1 trial showed a response rate of $78 \%$ in MPM patients receiving cisplatin-pemetrexed plus Adi-PEG20 [50]. NCT02709512 trial is currently recruiting mesothelioma patients to evaluate this triplet in tumors with low levels of ASS1 [108]. 


\subsection{Immunotherapeutic strategies: from immune checkpoint inhibition to adoptive cell therapy}

The relationship between immune system and cancer cells is well known. The immunoediting represents a dynamic process through which immunosurveillance can induce changes in immunogenicity of tumor cells, leading to the onset of immuneresistant variants [77].

Furthermore, the tumor microenvironment characterizing MPM plays a crucial role and it is characterized by the presence of immunosuppressive elements such as cytokines IL-6 and IL-8, regulatory T-cells (Tregs) and M2 polarized-tumor associated macrophages $[109,110]$. Notably, a worse outcome has been shown to be related with high CD63+ tumor-associated macrophages and low CD8+ tumor infiltrating lymphocytes; conversely, tumors with low CD163+ associated macrophages and high CD20+ lymphocytes had better prognosis [111,112].

One of the main mechanism of immunosurveillance escape is represented by the upregulation of cancer cell surface inhibitory ligands; as such, several clinical trials have been conducted or are currently ongoing to determine the role of checkpoint inhibitors in mesothelioma patients, mainly based on the positive results of these agents in a variety of solid tumors. Indeed, through their ability to block the inhibitory signaling, checkpoint blockers may prevent the downregulation of immune system. Programmed death-1 (PD-1) is a key immune checkpoint receptor expressed on the surface of activated lymphocytes and natural killer cells. Its binding with the programmed death ligand-1 and 2 (PD-L1 and PD-L2) on cancer and stromal cells, leads to immune cells exhaustion and tumor proliferation [77]. PD-L1 is expressed in about $16-40 \%$ of MPM, with a higher frequency in sarcomatoid subtype. Furthermore, 
PD-L1 positivity has been shown to be associated with worse prognosis and to play a crucial role in determining the efficacy of anti-PD-1 novel agents [113].

The phase Ib KEYNOTE-028 trial reported a $40 \%$ clinical benefit rate with manageable toxicity in PD-L1 positive MPM patients receiving monotherapy with the anti-PD-1 monoclonal antibody pembrolizumab [114]. A phase II clinical trial described a clinically significant single-agent activity in previously treated patients unselected for PDL-1, reporting a $19 \%$ RR and a $66 \%$ disease control rate. Moreover, the authors described higher RR and prolonged PFS with increasing PD-L1 expression [115].

The anti-PD-1 Nivolumab has also been investigated in second or subsequent lines of therapy. A phase II study reported a disease control rate at 12 weeks of $50 \%$, meeting its primary endpoint [116]. Goto and colleagues presented at 2017 World Conference of Lung Cancer (WCLC) the preliminary results of the MERIT trial, a phase II multicenter, open-label, single arm study. The ORR achieved in the Nivolumab arm was $29.4 \%$, the median PFS was 6.1 months (95\%IC:2.9-NR) and the median OS was not reached yet [117]. Nivolumab confirmed to be effective and safe, as single agent therapy, in a real life setting and in MM patients with an ECOG performance status $\geq$ $2[118]$.

Avelumab, a monoclonal antibody directed against PD-L1, has being investigated in the phase Ib JAVELIN study; an ORR of $14.3 \%$ and $8 \%$ in PD-L1 positive and PD-L1 negative MPM patients, respectively, has been reported [119].

Other immune checkpoint inhibitors, such as the cytotoxic T-lymphocyte antigen 4 (CTLA-4) inhibitor Tremelimumab, were studied in clinical trials. CTLA-4 is a glycoprotein expressed by activated T lymphocytes and Tregs, which induces an immune inhibitory signaling through its binding to the ligand B7 [77]. A phase II study by Calabrò et al showed a durable partial response rate of $7 \%$ in pretreated MPM 
patients receiving Tremelimumab $15 \mathrm{mg} / \mathrm{kg}$ every 3 months, though the primary endpoint was not met [120]. Another phase II trial assessed the role of an intensive schedule of tremelimumab $(10 \mathrm{mg} / \mathrm{kg}$ every 28 days for 6 cycles, followed by maintenance with tremelimumab every 3 months) showing a control rate of $52 \%$ and partial response in 4 out of 29 patients [121]. However, the results of a large phase II DETERMINE trial reported no survival benefit from tremelimumab compared with placebo in the intention-to-treat population (7.7 vs 7.3 months, HR 0.92, $p=0.41$ ) [122]. The combination of CTLA-4 inhibitors with PD-1/PD-L1 inhibitors is currently under investigation, in order to improve efficacy of mesothelioma systemic treatment. Preliminary results of a randomized phase II trial evaluating Nivolumab, with or without Ipilimumab, in pretreated MPM patients have been presented at the 2017 ESMO annual meeting. The authors showed an ORR of $27.8 \%$ in the combination-therapy group, compared with $18.5 \%$ in patients receiving only Nivolumab. Disease control rates at 12 weeks was $50 \%$ and $44.4 \%$, respectively. Median PFS was 5.6 months for the combination arm and 4 months in the Nivolumab arm, median OS was not reached and 13.6 months, respectively [123].

Similar results were reported by Disselhorst at the 2017 WCLC with a disease control rate at 12 weeks of $28 \%$ for the Nivolumab plus Ipilimumab combination [124]. The combination of an anti CTLA-4 antibody, Tremelimumab, with an anti PDL-1 antibody, Durvalumab, was evaluated in a second line setting in the NIBIT-MESO 1 study. The authors found a $28 \%$ ORR and $65 \%$ disease control rate according to irRECIST. The median response duration was 16.1 months. No correlation between baseline PD-L1 and outcome measures was found [125].

Moreover, the integration of immunotherapy with $\mathrm{CT}$ and RT may potentially improve outcome in these patients. Indeed, some studies have suggested that hypofractionated 
high-dose RT may have an immunomodulatory synergistic effect through the upregulation of TILs and CD8 T Iymphocytes [2,126].

Also chemotherapy seems to have an immunostimulatory effect; as a matter of fact, metastatic breast cancer patients receiving taxanes were found to have an increase of immune-related cytokines and immune cells [2]. The combination of immunotherapy and CT has shown promising results in preclinical trials on mesothelioma cells [127]. In the phase II DREAM study, the addition of Durvalumab to standard first-line CT improved 6 months-PFS and ORR, with a good tolerability profile [128].

Immunotherapeutic vaccination and oncolytic virotherapy are also under investigation $[77,129]$. The adoptive cell therapy, by the utilization of genetically-modified $T$ cell receptor (TCR) and chimeric antigen receptor modified T cell (CAR T cell), represents another novel developing therapeutic strategy $[67,77]$.

Several clinical trials are currently ongoing to assess the efficacy of immunotherapeutic strategies and are shown in Table 1.

Table 1. Significant ongoing trials on immunotherapy in MPM patients (as of June 2019; "not yet recruiting" trials excluded)

\begin{tabular}{|c|c|c|c|}
\hline $\begin{array}{l}\text { Treatment } \\
\text { strategy }\end{array}$ & $\begin{array}{l}\text { Biological } \\
\text { target }\end{array}$ & Experimental drug & $\begin{array}{l}\text { Study number, } \\
\text { status, phase }\end{array}$ \\
\hline \multirow{6}{*}{$\begin{array}{c}\text { Immunotherapy } \\
\text { alone }\end{array}$} & \multirow{6}{*}{ PD-1 } & \multirow{6}{*}{ Pembrolizumab } & $\begin{array}{l}\text { NCT02707666, } \\
\text { recruiting, phase } 1\end{array}$ \\
\hline & & & $\begin{array}{l}\text { NCT02784171, } \\
\text { recruiting, phase 2 }\end{array}$ \\
\hline & & & $\begin{array}{l}\text { NCT02959463, } \\
\text { recruiting, phase } 1\end{array}$ \\
\hline & & & $\begin{array}{l}\text { NCT02399371, } \\
\text { active not recruiting, } \\
\text { phase } 2\end{array}$ \\
\hline & & & $\begin{array}{l}\text { NCT02991482, } \\
\text { active not recruiting, } \\
\text { phase } 3\end{array}$ \\
\hline & & & $\begin{array}{l}\text { NCT03126630, } \\
\text { recruiting, phase 1/2 }\end{array}$ \\
\hline
\end{tabular}




\begin{tabular}{|c|c|c|c|}
\hline & & Nivolumab & $\begin{array}{l}\text { NCT03063450, } \\
\text { recruiting, phase } 3 \\
\text { NCT02497508, } \\
\text { completed, phase } 2\end{array}$ \\
\hline & PD-L1 & Durvalumab & $\begin{array}{l}\text { NCT01772004, } \\
\text { active not recruiting, } \\
\text { phase } 1\end{array}$ \\
\hline & CTLA-4 & Tremelimumab & $\begin{array}{l}\text { NCT01843374, } \\
\text { active not recruiting, } \\
\text { phase } 2\end{array}$ \\
\hline & & & $\begin{array}{l}\text { NCT02716272, } \\
\text { active not recruiting, } \\
\text { phase } 2\end{array}$ \\
\hline & PD-1 plus CTLA-4 & $\begin{array}{l}\text { Nivolumab plus } \\
\text { ipilimumab }\end{array}$ & $\begin{array}{l}\text { NCT02899299, } \\
\text { active not recruiting, } \\
\text { phase } 3\end{array}$ \\
\hline & & & $\begin{array}{l}\text { NCT03048474, } \\
\text { active not recruiting, } \\
\text { phase } 2\end{array}$ \\
\hline & & & $\begin{array}{l}\text { NCT02592551, } \\
\text { recruiting, phase } 2\end{array}$ \\
\hline & PD-L1 plus CTLA- & Durvalumab plus & $\begin{array}{l}\text { NCT02588131, } \\
\text { recruitment status } \\
\text { unknown, phase } 2\end{array}$ \\
\hline & 4 & tremelimumab & $\begin{array}{l}\text { NCT03075527, } \\
\text { suspended (interim } \\
\text { analysis), phase } 2\end{array}$ \\
\hline & & & $\begin{array}{l}\text { NCT02141347, } \\
\text { completed, phase } 1\end{array}$ \\
\hline & CD26 & YS110 & $\begin{array}{l}\text { NCT03177668, } \\
\text { active not recruiting, } \\
\text { phase } 1 / 2\end{array}$ \\
\hline & $\begin{array}{c}\text { PD-L1 plus } \\
\text { chemotherapy }\end{array}$ & Durvalumab & $\begin{array}{l}\text { NCT02899195, } \\
\text { active not recruiting, } \\
\text { phase } 2\end{array}$ \\
\hline $\begin{array}{c}\text { Immunotherapy } \\
\text { plus chemotherapy }\end{array}$ & $\begin{array}{c}\text { PD-L1 plus } \\
\text { chemotherapy } \\
\text { and radiotherapy. }\end{array}$ & Atezolizumab & $\begin{array}{l}\text { NCT03228537, } \\
\text { recruiting, phase } 1\end{array}$ \\
\hline & $\begin{array}{c}\text { PD-L1 plus VEGF } \\
\text { and } \\
\text { chemotherapy }\end{array}$ & $\begin{array}{c}\text { Atezolizumab plus } \\
\text { bevacizumab plus } \\
\text { chemotherapy } \\
\end{array}$ & $\begin{array}{l}\text { NCT03762018, } \\
\text { recruting, phase } 3\end{array}$ \\
\hline & & LMB-100 & $\begin{array}{l}\text { NCT02798536, } \\
\text { active not recruiting, } \\
\text { phase } 1\end{array}$ \\
\hline & Mesothelin & $\begin{array}{c}\text { LMB-100 plus SEL- } \\
110\end{array}$ & $\begin{array}{l}\text { NCT03436732, } \\
\text { completed, phase } 1\end{array}$ \\
\hline Anti-mesothelin & $\begin{array}{l}\text { targeted } \\
\text { immunotoxin }\end{array}$ & $\begin{array}{l}\text { LMB-100 followed by } \\
\text { pembrolizumab }\end{array}$ & $\begin{array}{l}\text { NCT03644550, } \\
\text { recruiting, phase } 2\end{array}$ \\
\hline & & SS1P & $\begin{array}{l}\text { NCT01362790, } \\
\text { completed, phase } \\
1 / 2\end{array}$ \\
\hline & & & NCT00006981, \\
\hline
\end{tabular}




\begin{tabular}{|c|c|c|c|}
\hline & & & completed, phase 1 \\
\hline & & $\begin{array}{c}\text { SS1P plus } \\
\text { chemotherapy }\end{array}$ & $\begin{array}{l}\text { NCT01445392, } \\
\text { terminated, phase } 1\end{array}$ \\
\hline & & & $\begin{array}{l}\text { NCT01265433, } \\
\text { completed, phase } 2\end{array}$ \\
\hline & $\begin{array}{c}\text { Wilms tumor gene } \\
\text { (WT-1) }\end{array}$ & vaccine & $\begin{array}{l}\text { NCT01890980, } \\
\text { active not recruiting, } \\
\text { phase } 2\end{array}$ \\
\hline & & $\begin{array}{l}\text { WT1-targeted } \\
\text { dendritic cell } \\
\text { vaccinations }\end{array}$ & $\begin{array}{l}\text { NCT02649829, } \\
\text { recruiting, phase 1/2 }\end{array}$ \\
\hline Vaccines & Dendritic cells & $\begin{array}{l}\text { DC vaccine plus } \\
\text { chemokine } \\
\text { modulatory regimen }\end{array}$ & $\begin{array}{l}\text { NCT02151448, } \\
\text { completed, phase } \\
1 / 2\end{array}$ \\
\hline & & $\begin{array}{l}\text { DC immunotherapy } \\
\text { plus MesoPher }\end{array}$ & $\begin{array}{l}\text { NCT03610360, } \\
\text { recruiting, phase 2/3 }\end{array}$ \\
\hline & & GL-ONC1 & $\begin{array}{l}\text { NCT02714374, } \\
\text { active not recruiting, } \\
\text { phase } 1 b\end{array}$ \\
\hline & Uncolytic virus & Intrapleural GL-ONC1 & $\begin{array}{l}\text { NCT01766739, } \\
\text { active not recruiting, } \\
\text { phase } 1\end{array}$ \\
\hline & TCR & TCR targeting WT-1 & $\begin{array}{l}\text { NCT02408016, } \\
\text { active not recruiting, } \\
\text { phase } 1 / 2\end{array}$ \\
\hline & & & $\begin{array}{l}\text { NCT02414269, } \\
\text { recruiting, phase } 1\end{array}$ \\
\hline & & & $\begin{array}{l}\text { NCT03907852, } \\
\text { recruting, phase 1/2 }\end{array}$ \\
\hline Adoptive cell & & & $\begin{array}{l}\text { NCT03054298, } \\
\text { recruting, phase } 1\end{array}$ \\
\hline therapy & CAR T cell & $\begin{array}{l}\text { CAR T cell targeting } \\
\text { mesothelin }\end{array}$ & $\begin{array}{l}\text { NCT02580747, } \\
\text { recruitment status } \\
\text { unknown, phase } 1\end{array}$ \\
\hline & & & $\begin{array}{l}\text { NCT03638206, } \\
\text { recruiting, phase 1/2 }\end{array}$ \\
\hline & & & $\begin{array}{l}\text { NCT01583686, } \\
\text { terminated, phase } \\
1 / 2\end{array}$ \\
\hline & & & $\begin{array}{l}\text { NCT01355965, } \\
\text { completed, phase } 1\end{array}$ \\
\hline
\end{tabular}

\section{Conclusions}

The management of MPM still represents a critical challenge. The combination of platinum compounds plus pemetrexed, with or without bevacizumab, is currently the standard first-line CT for MPM patients. Despite the systemic treatment, the prognosis 
of these patients remains poor, with median OS of approximately 12 months [3]. Many therapeutic strategies have been studied or are under development in order to improve the outcome of MPM patients, focusing on the underlying biology and molecular pathways of the disease. Immunotherapy is one of the most promising new therapeutic strategies, with several trials ongoing or already completed. Given the results of the above-mentioned studies by Alley and Zalcman [114,123], the last version of NCCN guidelines has incorporated Pembrolizumab and Nivolumab with or without Ipilimumab as a treatment option for MPM patients after progression on first-line CT. Based on a subset analysis of these trials, PDL-1 expression seems to be a useful biomarker in identifying patients more likely to benefit from immunotherapeutic strategies. However, these results should be interpreted cautiously, due to the small sample size of the studies.

When considering data from immunotherapy clinical trials, whether positive or negative, it should not be underestimated the limited mutation rate and the consequent low formation of antigens characterizing mesothelioma tumors [2]. This aspect, together with the immunosuppressive pattern of MPM microenvironment, may partially explain the poor efficacy of some novel therapeutic agents.

Additionally, the blockade of immune checkpoints may lead to the upregulation of alternative inhibitory checkpoints, which may result in an adaptive resistance to PD-1 and PD-L1 inhibitors [77]. Regarding immunotoxin-based immunotherapy and oncolytic virotherapy, the development of patient-derived antibodies able to neutralize the toxin or the virus could decrease the therapeutic effects.

The current lack of validated biomarkers capable to identify the patients more likely to derive benefit from immunotherapy or other treatment strategies, represents a further 
critical challenge. Similarly, no biomarker predicting the safety of such drugs and the probability of immune-related toxicity has been identified yet.

A thorough knowledge of mesothelioma biology and microenvironment will be determinant to overcome the mechanisms of resistance and to develop tailored effective treatments.

Despite the many promising results, to date patients' participation in clinical trials should be encouraged whenever possible.

\section{AUTHOR CONTRIBUTIONS}

All authors actively contributed to draft the manuscript. The last author was involved in revising the manuscript critically for important intellectual content. All authors read and approved the final version of the manuscript.

\section{Conflict of Interest Statement}

None.

No conflict of interest nor funding is to be declared for the handwriting of this manuscript

\section{DISCLOSURES}

No conflict of interest nor funding is to be declared for the handwriting of this manuscript.

\section{REFERENCES}


[1] Carbone M, Ly BH, Dodson RF, Pagano I, Morris PT, Dogan UA, et al. Malignant mesothelioma: facts, myths, and hypotheses. J Cell Physiol 2012;227:4458. doi:10.1002/jcp.22724.

[2] Wu L, de Perrot M. Radio-immunotherapy and chemo-immunotherapy as a novel treatment paradigm in malignant pleural mesothelioma. Transl Lung Cancer Res 2017;6:325-34. doi:10.21037/tlcr.2017.06.03.

[3] Mancuso MR, Neal JW. Novel systemic therapy against malignant pleural mesothelioma. Transl Lung Cancer Res 2017;6:295-314. doi:10.21037/tlcr.2017.06.01.

[4] Patel SC, Dowell JE. Modern management of malignant pleural mesothelioma. Lung Cancer 2016;7:63-72. doi:10.2147/LCTT.S83338.

[5] Herndon JE, Green MR, Chahinian AP, Corson JM, Suzuki Y, Vogelzang NJ. Factors predictive of survival among 337 patients with mesothelioma treated between 1984 and 1994 by the Cancer and Leukemia Group B. Chest 1998;113:723-31.

[6] Curran D, Sahmoud T, Therasse P, van Meerbeeck J, Postmus PE, Giaccone G. Prognostic factors in patients with pleural mesothelioma: the European Organization for Research and Treatment of Cancer experience. J Clin Oncol 1998;16:145-52. doi:10.1200/JCO.1998.16.1.145.

[7] Vogelzang NJ, Rusthoven JJ, Symanowski J, Denham C, Kaukel E, Ruffie P, et al. Phase III study of pemetrexed in combination with cisplatin versus cisplatin alone in patients with malignant pleural mesothelioma. J Clin Oncol 2003;21:2636-44. doi:10.1200/JCO.2003.11.136.

[8] Cinausero M, Rihawi K, Sperandi F, Melotti B, Ardizzoni A. Chemotherapy treatment in malignant pleural mesothelioma: a difficult history. $J$ Thorac Dis 2018;10:S304-10. doi:10.21037/jtd.2017.10.19.

[9] Yap TA, Aerts JG, Popat S, Fennell DA. Novel insights into mesothelioma biology and implications for therapy. Nat Rev Cancer 2017;17:475-88. doi:10.1038/nrc.2017.42.

[10] Sekido Y. Molecular biology of malignant mesothelioma. Environ Health Prev Med 2008;13:65-70. doi:10.1007/s12199-007-0015-8.

[11] Nasu M, Emi M, Pastorino S, Tanji M, Powers A, Luk H, et al. High Incidence of Somatic BAP1 alterations in sporadic malignant mesothelioma. J Thorac Oncol Off Publ Int Assoc Study Lung Cancer 2015;10:565-76. doi:10.1097/JTO.0000000000000471. 
[12] Woodard GA, Yang Y-L, You L, Jablons DM. Drug development against the hippo pathway in mesothelioma. Transl Lung Cancer Res 2017;6:335-42. doi:10.21037/tlcr.2017.06.02.

[13] Bueno R, Stawiski EW, Goldstein LD, Durinck S, De Rienzo A, Modrusan Z, et al. Comprehensive genomic analysis of malignant pleural mesothelioma identifies recurrent mutations, gene fusions and splicing alterations. Nat Genet 2016;48:407-16. doi:10.1038/ng.3520.

[14] Maziak DE, Gagliardi A, Haynes AE, Mackay JA, Evans WK, Cancer Care Ontario Program in Evidence-based Care Lung Cancer Disease Site Group. Surgical management of malignant pleural mesothelioma: a systematic review and evidence summary. Lung Cancer 2005;48:157-69. doi:10.1016/j.lungcan.2004.11.003.

[15] Cao C, Yan TD, Bannon PG, McCaughan BC. Summary of prognostic factors and patient selection for extrapleural pneumonectomy in the treatment of malignant pleural mesothelioma. Ann Surg Oncol 2011;18:2973-9. doi:10.1245/s10434-0111728-x.

[16] Flores RM, Pass HI, Seshan VE, Dycoco J, Zakowski M, Carbone M, et al. Extrapleural pneumonectomy versus pleurectomy/decortication in the surgical management of malignant pleural mesothelioma: results in 663 patients. J Thorac Cardiovasc Surg 2008;135:620-6, 626-3. doi:10.1016/j.jtcvs.2007.10.054.

[17] Cao C, Tian D, Park J, Allan J, Pataky KA, Yan TD. A systematic review and meta-analysis of surgical treatments for malignant pleural mesothelioma. Lung Cancer 2014;83:240-5. doi:10.1016/j.lungcan.2013.11.026.

[18] Rusch VW, Rosenzweig K, Venkatraman E, Leon L, Raben A, Harrison L, et al. A phase II trial of surgical resection and adjuvant high-dose hemithoracic radiation for malignant pleural mesothelioma. J Thorac Cardiovasc Surg 2001;122:788-95. doi:10.1067/mtc.2001.116560.

[19] Cho BCJ, Feld R, Leighl N, Opitz I, Anraku M, Tsao M-S, et al. A feasibility study evaluating Surgery for Mesothelioma After Radiation Therapy: the "SMART" approach for resectable malignant pleural mesothelioma. J Thorac Oncol 2014;9:397-402. doi:10.1097/JTO.0000000000000078.

[20] Rimner A, Zauderer MG, Gomez DR, Adusumilli PS, Parhar PK, Wu AJ, et al. Phase II Study of Hemithoracic Intensity-Modulated Pleural Radiation Therapy (IMPRINT) As Part of Lung-Sparing Multimodality Therapy in Patients With Malignant Pleural Mesothelioma. J Clin Oncol 2016;34:2761-8. doi:10.1200/JCO.2016.67.2675. 
[21] Krug LM, Pass HI, Rusch VW, Kindler HL, Sugarbaker DJ, Rosenzweig KE, et al. Multicenter phase II trial of neoadjuvant pemetrexed plus cisplatin followed by extrapleural pneumonectomy and radiation for malignant pleural mesothelioma. J Clin Oncol 2009;27:3007-13. doi:10.1200/JCO.2008.20.3943.

[22] Treasure T, Lang-Lazdunski L, Waller D, Bliss JM, Tan C, Entwisle J, et al. Extra-pleural pneumonectomy versus no extra-pleural pneumonectomy for patients with malignant pleural mesothelioma: clinical outcomes of the Mesothelioma and Radical Surgery (MARS) randomised feasibility study. Lancet Oncol 2011;12:763-72. doi:10.1016/S1470-2045(11)70149-8.

[23] Tsao AS, Wistuba I, Roth JA, Kindler HL. Malignant pleural mesothelioma. J Clin Oncol 2009;27:2081-90. doi:10.1200/JCO.2008.19.8523.

[24] Muers MF, Stephens RJ, Fisher P, Darlison L, Higgs CMB, Lowry E, et al. Active symptom control with or without chemotherapy in the treatment of patients with malignant pleural mesothelioma (MS01): a multicentre randomised trial. Lancet 2008;371:1685-94. doi:10.1016/S0140-6736(08)60727-8.

[25] van Meerbeeck JP, Gaafar R, Manegold C, Van Klaveren RJ, Van Marck EA, Vincent M, et al. Randomized phase III study of cisplatin with or without raltitrexed in patients with malignant pleural mesothelioma: an intergroup study of the European Organisation for Research and Treatment of Cancer Lung Cancer Group and the National Cancer Institute of Canada. J Clin Oncol 2005;23:6881-9. doi:10.1200/JCO.20005.14.589.

[26] Castagneto B, Botta M, Aitini E, Spigno F, Degiovanni D, Alabiso O, et al. Phase II study of pemetrexed in combination with carboplatin in patients with malignant pleural mesothelioma (MPM). Ann Oncol 2008;19:370-3. doi:10.1093/annonc/mdm501.

[27] Ceresoli GL, Zucali PA, Favaretto AG, Grossi F, Bidoli P, Del Conte G, et al. Phase II study of pemetrexed plus carboplatin in malignant pleural mesothelioma. J Clin Oncol 2006;24:1443-8. doi:10.1200/JCO.2005.04.3190.

[28] Katirtzoglou N, Gkiozos I, Makrilia N, Tsaroucha E, Rapti A, Stratakos G, et al. Carboplatin plus pemetrexed as first-line treatment of patients with malignant pleural mesothelioma: a phase II study. Clin Lung Cancer 2010;11:30-5. doi:10.3816/CLC.2010.n.005.

[29] Ceresoli GL, Castagneto B, Zucali PA, Favaretto A, Mencoboni M, Grossi F, et al. Pemetrexed plus carboplatin in elderly patients with malignant pleural 
mesothelioma: combined analysis of two phase II trials. Br J Cancer 2008;99:51-6. doi:10.1038/sj.bjc.6604442.

[30] Santoro A, O'Brien ME, Stahel RA, Nackaerts K, Baas P, Karthaus M, et al. Pemetrexed plus cisplatin or pemetrexed plus carboplatin for chemonaïve patients with malignant pleural mesothelioma: results of the International Expanded Access Program. J Thorac Oncol 2008;3:756-63. doi:10.1097/JTO.0b013e31817c73d6.

[31] Kalmadi SR, Rankin C, Kraut MJ, Jacobs AD, Petrylak DP, Adelstein DJ, et al. Gemcitabine and cisplatin in unresectable malignant mesothelioma of the pleura: a phase II study of the Southwest Oncology Group (SWOG 9810). Lung Cancer 2008;60:259-63. doi:10.1016/j.lungcan.2007.09.018.

[32] Favaretto AG, Aversa SML, Paccagnella A, Manzini VDP, Palmisano V, Oniga $F$, et al. Gemcitabine combined with carboplatin in patients with malignant pleural mesothelioma: a multicentric phase II study. Cancer 2003;97:2791-7. doi:10.1002/cncr.11405.

[33] Ardizzoni A, Rosso R, Salvati F, Fusco V, Cinquegrana A, De Palma M, et al. Activity of doxorubicin and cisplatin combination chemotherapy in patients with diffuse malignant pleural mesothelioma. An Italian Lung Cancer Task Force (FONICAP) Phase II study. Cancer 1991;67:2984-7.

[34] Berghmans T, Lafitte JJ, Paesmans M, Stach B, Berchier MC, Wackenier P, et al. A phase II study evaluating the cisplatin and epirubicin combination in patients with unresectable malignant pleural mesothelioma. Lung Cancer 2005;50:75-82. doi:10.1016/j.lungcan.2005.05.007.

[35] Ceresoli GL, Zucali PA, Mencoboni M, Botta M, Grossi F, Cortinovis D, et al. Phase II study of pemetrexed and carboplatin plus bevacizumab as first-line therapy in malignant pleural mesothelioma. $\mathrm{Br} J$ Cancer 2013;109:552-8. doi:10.1038/bjc.2013.368.

[36] Zalcman G, Mazieres J, Margery J, Greillier L, Audigier-Valette C, Moro-Sibilot $D$, et al. Bevacizumab for newly diagnosed pleural mesothelioma in the Mesothelioma Avastin Cisplatin Pemetrexed Study (MAPS): a randomised, controlled, open-label, phase 3 trial. Lancet 2016;387:1405-14. doi:10.1016/S0140-6736(15)01238-6.

[37] O'Brien MER, Watkins D, Ryan C, Priest K, Corbishley C, Norton A, et al. A randomised trial in malignant mesothelioma $(M)$ of early $(E)$ versus delayed $(D)$ chemotherapy in symptomatically stable patients: the MED trial. Ann Oncol 2006;17:270-5. doi:10.1093/annonc/mdj073. 
[38] Manegold C, Symanowski J, Gatzemeier U, Reck M, von Pawel J, Kortsik C, et al. Second-line (post-study) chemotherapy received by patients treated in the phase III trial of pemetrexed plus cisplatin versus cisplatin alone in malignant pleural mesothelioma. Ann Oncol 2005;16:923-7. doi:10.1093/annonc/mdi187.

[39] Jassem J, Ramlau R, Santoro A, Schuette W, Chemaissani A, Hong S, et al. Phase III trial of pemetrexed plus best supportive care compared with best supportive care in previously treated patients with advanced malignant pleural mesothelioma. $J$ Clin Oncol 2008;26:1698-704. doi:10.1200/JCO.2006.09.9887.

[40] Zucali PA, Simonelli M, Michetti G, Tiseo M, Ceresoli GL, Collovà E, et al. Second-line chemotherapy in malignant pleural mesothelioma: results of a retrospective multicenter survey. Lung Cancer Amst Neth 2012;75:360-7. doi:10.1016/j.lungcan.2011.08.011.

[41] Skubitz KM. Phase II trial of pegylated-liposomal doxorubicin (Doxil) in mesothelioma. Cancer Invest 2002;20:693-9.

[42] Stebbing J, Powles T, McPherson K, Shamash J, Wells P, Sheaff MT, et al. The efficacy and safety of weekly vinorelbine in relapsed malignant pleural mesothelioma. Lung Cancer 2009;63:94-7. doi:10.1016/j.lungcan.2008.04.001.

[43] Toyokawa G, Takenoyama M, Hirai F, Toyozawa R, Inamasu E, Kojo M, et al. Gemcitabine and vinorelbine as second-line or beyond treatment in patients with malignant pleural mesothelioma pretreated with platinum plus pemetrexed chemotherapy. Int J Clin Oncol 2014;19:601-6. doi:10.1007/s10147-013-0619-5.

[44] Vogelzang NJ. Gemcitabine and cisplatin: second-line chemotherapy for malignant mesothelioma? J Clin Oncol 1999;17:2626-7.

[45] Fennell DA, Steele JPC, Shamash J, Evans MT, Wells P, Sheaff MT, et al. Efficacy and safety of first- or second-line irinotecan, cisplatin, and mitomycin in mesothelioma. Cancer 2007;109:93-9. doi:10.1002/cncr.22366.

[46] Fizazi K, Doubre H, Le Chevalier T, Riviere A, Viala J, Daniel C, et al. Combination of raltitrexed and oxaliplatin is an active regimen in malignant mesothelioma: results of a phase II study. J Clin Oncol 2003;21:349-54. doi:10.1200/JCO.2003.05.123.

[47] Porta C, Zimatore M, Bonomi L, Imarisio I, Paglino C, Sartore-Bianchi A, et al. Raltitrexed-Oxaliplatin combination chemotherapy is inactive as second-line treatment for malignant pleural mesothelioma patients. Lung Cancer 2005;48:429-34. doi:10.1016/j.lungcan.2004.11.015. 
[48] Pemetrexed Disodium/Observation in Treating Patients W/ Malignant Pleural Mesothelioma w/Out Progressive Disease After 1st Line Chemotherapy https://clinicaltrials.gov/ct2/show/NCT01085630

[49] Ceresoli GL, Zucali PA, De Vincenzo F, Gianoncelli L, Simonelli M, Lorenzi E, et al. Retreatment with pemetrexed-based chemotherapy in patients with malignant pleural mesothelioma. Lung Cancer 2011;72:73-7. doi:10.1016/j.lungcan.2010.12.004.

[50] McCambridge AJ, Napolitano A, Mansfield AS, Fennell DA, Sekido Y, Nowak AK, et al. Progress in the Management of Malignant Pleural Mesothelioma in 2017. J Thorac Oncol 2018;13:606-23. doi:10.1016/j.jtho.2018.02.021.

[51] Buikhuisen WA, Burgers JA, Vincent AD, Korse CM, van Klaveren RJ, Schramel $\mathrm{FMNH}$, et al. Thalidomide versus active supportive care for maintenance in patients with malignant mesothelioma after first-line chemotherapy (NVALT 5): an open-label, multicentre, randomised phase 3 study. Lancet Oncol 2013;14:543-51. doi:10.1016/S1470-2045(13)70125-6.

[52] Grosso F, Steele N, Novello S, Nowak AK, Popat S, Greillier L, et al. Nintedanib Plus Pemetrexed/Cisplatin in Patients With Malignant Pleural Mesothelioma: Phase II Results From the Randomized, Placebo-Controlled LUME-Meso Trial. J Clin Oncol 2017;35:3591-600. doi:10.1200/JCO.2017.72.9012.

[53] Scagliotti G, Gaafar R, Novak AK, Nakano T, Van Meerbeeck J, Popat S, et al. PL02.09 Nintedanib + Pemetrexed/Cisplatin in Patients with Unresectable MPM: Phase III Results from the LUME-Meso Trial. Presented at WCLC 2018 19th World Conference Lung Cancer

[54] Campbell NP, Kunnavakkam R, Leighl N, Vincent MD, Gandara DR, Koczywas $\mathrm{M}$, et al. Cediranib in patients with malignant mesothelioma: a phase II trial of the University of Chicago Phase II Consortium. Lung Cancer 2012;78:76-80. doi:10.1016/j.lungcan.2012.06.011.

[55] Garland LL, Chansky K, Wozniak AJ, Tsao AS, Gadgeel SM, Verschraegen CF, et al. Phase II study of cediranib in patients with malignant pleural mesothelioma: SWOG S0509. J Thorac Oncol 2011;6:1938-45. doi:10.1097/JTO.0b013e318229586e.

[56] Tsao AS, Moon J, Wistuba II, Vogelzang NJ, Kalemkerian GP, Redman MW, et al. Phase I Trial of Cediranib in Combination with Cisplatin and Pemetrexed in Chemonaive Patients with Unresectable Malignant Pleural Mesothelioma (SWOG 
S0905). J Thorac Oncol 2017;12:1299-308. doi:10.1016/j.jtho.2017.05.021.

[57] Anne S. Tsao. SWOG S0905: A randomized phase II study of cediranib versus placebo in combination with cisplatin and pemetrexed in chemonaive patients with malignant pleural mesothelioma. J Clin Oncol 2018;36:(suppl; abstr 8514).

[58] Laurie SA, Gupta A, Chu Q, Lee CW, Morzycki W, Feld R, et al. Brief report: a phase II study of sunitinib in malignant pleural mesothelioma. the NCIC Clinical Trials Group. J Thorac Oncol 2011;6:1950-4. doi:10.1097/JTO.0b013e3182333df5.

[59] Jahan T, Gu L, Kratzke R, Dudek A, Otterson GA, Wang X, et al. Vatalanib in malignant mesothelioma: a phase II trial by the Cancer and Leukemia Group B (CALGB 30107). Lung Cancer 2012;76:393-6. doi:10.1016/j.lungcan.2011.11.014.

[60] Dubey S, Jänne PA, Krug L, Pang H, Wang X, Heinze R, et al. A phase II study of sorafenib in malignant mesothelioma: results of Cancer and Leukemia Group B 30307. J Thorac Oncol 2010;5:1655-61. doi:10.1097/JTO.0b013e3181ec18db.

[61] Papa S, Popat S, Shah R, Prevost AT, Lal R, McLennan B, et al. Phase 2 study of sorafenib in malignant mesothelioma previously treated with platinum-containing chemotherapy. J Thorac Oncol 2013;8:783-7. doi:10.1097/JTO.0b013e31828c2b26.

[62] Pignochino Y, Dell'Aglio C, Inghilleri S, Zorzetto M, Basiricò M, Capozzi F, et al. The combination of sorafenib and everolimus shows antitumor activity in preclinical models of malignant pleural mesothelioma. BMC Cancer 2015;15:374. doi:10.1186/s12885-015-1363-1.

[63] Leon LG, Gemelli M, Sciarrillo R, Avan A, Funel N, Giovannetti E. Synergistic activity of the c-Met and tubulin inhibitor tivantinib (ARQ197) with pemetrexed in mesothelioma cells. Curr Drug Targets 2014;15:1331-40.

[64] Study of the Combination of Tivantinib Plus Pemetrexed and Carboplatin https://clinicaltrials.gov/ct2/show/NCT02049060.

[65] Vanesa Gregorc, Chiara Lazzari, Alessandra Bulotta, Maria Grazia Viganò, Domenico Ghio, Floriana Fontana, Giulia Salini, Antonio Lambiase. Long-term survival outcomes of a placebo-controlled phase 3 trial with NGR-hT. J Clin Oncol 2018;36:(suppl; abstr 8567).

[66] Gregorc V, Gaafar RM, Favaretto A, Grossi F, Jassem J, Polychronis A, et al. NGR-hTNF in combination with best investigator choice in previously treated malignant pleural mesothelioma (NGR015): a randomised, double-blind, placebo-controlled phase 3 trial. Lancet Oncol 2018;19:799-811. doi:10.1016/S1470-2045(18)30193-1.

[67] Katzman D, Sterman DH. Updates in the diagnosis and treatment of malignant 
pleural mesothelioma. Curr Opin Pulm Med 2018;24:319-26. doi:10.1097/MCP.0000000000000489.

[68] Kiesgen S, Chicaybam L, Chintala NK, Adusumilli PS. Chimeric Antigen Receptor (CAR) T-Cell Therapy for Thoracic Malignancies. J Thorac Oncol 2018;13:16-26. doi:10.1016/j.jtho.2017.10.001.

[69] Fujisaka Y, Kurata T, Tanaka K, Kudo T, Okamoto K, Tsurutani J, et al. Phase I study of amatuximab, a novel monoclonal antibody to mesothelin, in Japanese patients with advanced solid tumors. Invest New Drugs 2015;33:380-8. doi:10.1007/s10637-014-0196-0.

[70] Hassan R, Cohen SJ, Phillips M, Pastan I, Sharon E, Kelly RJ, et al. Phase I clinical trial of the chimeric anti-mesothelin monoclonal antibody MORAb-009 in patients with mesothelin-expressing cancers. Clin Cancer Res 2010;16:6132-8. doi:10.1158/1078-0432.CCR-10-2275.

[71] Hassan R, Kindler HL, Jahan T, Bazhenova L, Reck M, Thomas A, et al. Phase II clinical trial of amatuximab, a chimeric antimesothelin antibody with pemetrexed and cisplatin in advanced unresectable pleural mesothelioma. Clin Cancer Res 2014;20:5927-36. doi:10.1158/1078-0432.CCR-14-0804.

[72] Study of the Safety and Efficacy of Amatuximab in Combination With Pemetrexed and Cisplatin in Subjects With Unresectable Malignant Pleural Mesothelioma (MPM). - https://clinicaltrials.gov/ct2/show/NCT02357147.

[73] Blumenschein GR, Hassan R, Moore KN, Santin A, Kindler HL, Nemunaitis JJ, et al. Phase I study of anti-mesothelin antibody drug conjugate anetumab ravtansine (AR). J Clin Oncol 2016;34:2509-2509. doi:10.1200/JCO.2016.34.15_suppl.2509.

[74] Phase lb Study of Anetumab Ravtansine in Combination With Pemetrexed and Cisplatin in Mesothelin-expressing Solid Tumors https://clinicaltrials.gov/ct2/show/NCT0263909.

[75] A Study of BMS-986148 in Patients With Select Advanced Solid Tumors https://clinicaltrials.gov/ct2/show/NCT02341625.

[76] Mesothelin-Targeted Immunotoxin LMB-100 in People With Malignant Mesothelioma - https://clinicaltrials.gov/ct2/show/NCT02798536.

[77] Dozier J, Zheng H, Adusumilli PS. Immunotherapy for malignant pleural mesothelioma: current status and future directions. Transl Lung Cancer Res 2017;6:315-24. doi:10.21037/tlcr.2017.05.02.

[78] Garland LL, Rankin C, Gandara DR, Rivkin SE, Scott KM, Nagle RB, et al. 
Phase II study of erlotinib in patients with malignant pleural mesothelioma: a Southwest Oncology Group Study. J Clin Oncol 2007;25:2406-13. doi:10.1200/JCO.2006.09.7634.

[79] Govindan R, Kratzke RA, Herndon JE, Niehans GA, Vollmer R, Watson D, et al. Gefitinib in patients with malignant mesothelioma: a phase II study by the Cancer and Leukemia Group B. Clin Cancer Res 2005;11:2300-4. doi:10.1158/10780432.CCR-04-1940.

[80] A Study of Cetuximab Combined With Cisplatin or Carboplatin/Pemetrexed as First Line Treatment in Patients With Malignant Pleural Mesothelioma. https://clinicaltrials.gov/ct2/show/NCT00996567

[81] Reid G, Pel ME, Kirschner MB, Cheng YY, Mugridge N, Weiss J, et al. Restoring expression of miR-16: a novel approach to therapy for malignant pleural mesothelioma. Ann Oncol 2013;24:3128-35. doi:10.1093/annonc/mdt412.

[82] van Zandwijk N, Pavlakis N, Kao SC, Linton A, Boyer MJ, Clarke S, et al. Safety and activity of microRNA-loaded minicells in patients with recurrent malignant pleural mesothelioma: a first-in-man, phase 1, open-label, dose-escalation study. Lancet Oncol 2017;18:1386-96. doi:10.1016/S1470-2045(17)30621-6.

[83] Mathy A, Baas P, Dalesio O, van Zandwijk N. Limited efficacy of imatinib mesylate in malignant mesothelioma: a phase II trial. Lung Cancer 2005;50:83-6. doi:10.1016/j.lungcan.2005.04.010.

[84] Tsao AS, Harun N, Lee JJ, Heymach J, Pisters K, Hong WK, et al. Phase I trial of cisplatin, pemetrexed, and imatinib mesylate in chemonaive patients with unresectable malignant pleural mesothelioma. Clin Lung Cancer 2014;15:197-201. doi:10.1016/j.cllc.2013.12.008.

[85] Ali Y, Lin Y, Gharibo MM, Gounder MK, Stein MN, Lagattuta TF, et al. Phase I and pharmacokinetic study of imatinib mesylate (Gleevec) and gemcitabine in patients with refractory solid tumors. Clin Cancer Res 2007;13:5876-82. doi:10.1158/10780432.CCR-07-0883.

[86] Combination of Gemcitabine and Imatinib Mesylate in Pemetrexed-pretreated Patients With Pleural Mesothelioma - https://clinicaltrials.gov/ct2/show/NCT02303899. [87] Dudek AZ, Pang H, Kratzke RA, Otterson GA, Hodgson L, Vokes EE, et al. Phase II study of dasatinib in patients with previously treated malignant mesothelioma (Cancer and Leukemia Group B 30601): a brief report. J Thorac Oncol 2012;7:755-9. doi:10.1097/JTO.0b013e318248242c. 
[88] Monica V, lacono ML, Bracco E, Busso S, Blasio LD, Primo L, et al. Dasatinib modulates sensitivity to pemetrexed in malignant pleural mesothelioma cell lines. Oncotarget 2016;7:76577-89. doi:10.18632/oncotarget.10428.

[89] Ou S-HI, Moon J, Garland LL, Mack PC, Testa JR, Tsao AS, et al. SWOG S0722: phase II study of mTOR inhibitor everolimus (RAD001) in advanced malignant pleural mesothelioma (MPM). J Thorac Oncol 2015;10:387-91. doi:10.1097/JTO.0000000000000360.

[90] Zou Y, Ge M, Wang X. Targeting PI3K-AKT-mTOR by LY3023414 inhibits human skin squamous cell carcinoma cell growth in vitro and in vivo. Biochem Biophys Res Commun 2017;490:385-92. doi:10.1016/j.bbrc.2017.06.052.

[91] Zaidi AH, Kosovec JE, Matsui D, Omstead AN, Raj M, Rao RR, et al. PI3K/mTOR Dual Inhibitor, LY3023414, Demonstrates Potent Antitumor Efficacy Against Esophageal Adenocarcinoma in a Rat Model. Ann Surg 2017;266:91-8. doi:10.1097/SLA.0000000000001908.

[92] Foley TM, Payne SN, Pasch CA, Yueh AE, Van De Hey DR, Korkos DP, et al. Dual PI3K/mTOR Inhibition in Colorectal Cancers with APC and PIK3CA Mutations. Mol Cancer Res MCR 2017;15:317-27. doi:10.1158/1541-7786.MCR-16-0256.

[93] A Study of LY3023414 in Participants With Advanced Cancer https://clinicaltrials.gov/ct2/show/NCT01655225.

[94] Dolly SO, Wagner AJ, Bendell JC, Kindler HL, Krug LM, Seiwert TY, et al. Phase I Study of Apitolisib (GDC-0980), Dual Phosphatidylinositol-3-Kinase and Mammalian Target of Rapamycin Kinase Inhibitor, in Patients with Advanced Solid Tumors. Clin Cancer Res 2016;22:2874-84. doi:10.1158/1078-0432.CCR-15-2225.

[95] Kanteti R, Riehm JJ, Dhanasingh I, Lennon FE, Mirzapoiazova T, Mambetsariev B, et al. PI3 Kinase Pathway and MET Inhibition is Efficacious in Malignant Pleural Mesothelioma. Sci Rep 2016;6:32992. doi:10.1038/srep32992.

[96] Krug LM, Kindler HL, Calvert H, Manegold C, Tsao AS, Fennell D, et al. Vorinostat in patients with advanced malignant pleural mesothelioma who have progressed on previous chemotherapy (VANTAGE-014): a phase 3, double-blind, randomised, placebo-controlled trial. Lancet Oncol 2015;16:447-56. doi:10.1016/S1470-2045(15)70056-2.

[97] Ramalingam SS, Belani CP, Ruel C, Frankel P, Gitlitz B, Koczywas M, et al. Phase II study of belinostat (PXD101), a histone deacetylase inhibitor, for second line therapy of advanced malignant pleural mesothelioma. J Thorac Oncol 2009;4:97-101. 
doi:10.1097/JTO.0b013e318191520c.

[98] Zauderer MG, , Peter Szlosarek, Sylvestre Le Moulec, Sanjay Popat, Paul Taylor, David Planchard. Phase 2, multicenter study of the EZH2 inhibitor tazemetostat as monotherapy in adults with relapsed or refractory $(R / R)$ malignant mesothelioma (MM) with BAP1 inactivation. J Clin Oncol 2018;36:(suppl; abstr 8515).

[99] Pachter JA, Kolev VN, Schunselaar L, Shapiro IM, Bueno R, Baas P, et al. Abstract 4236: FAK inhibitor VS-6063 (defactinib) targets mesothelioma cancer stem cells, which are enriched by standard of care chemotherapy. Cancer Res 2015;75:4236-4236. doi:10.1158/1538-7445.AM2015-4236.

[100] Shimizu T, Fukuoka K, Takeda M, Iwasa T, Yoshida T, Horobin J, et al. A firstin-Asian phase 1 study to evaluate safety, pharmacokinetics and clinical activity of VS6063, a focal adhesion kinase (FAK) inhibitor in Japanese patients with advanced solid tumors. Cancer Chemother Pharmacol 2016;77:997-1003. doi:10.1007/s00280-0163010-1.

[101] Dean Anthony Fennell PB, University of Leicester L, Netherlands Cancer Institute A, The University of Chicago C, Memorial Sloan Kettering Cancer Center NY, University of Western Australia and Sir Charles Gairdner Hospital N, et al. COMMAND: A phase II randomized, double-blind, placebo-controlled, multicenter study of defactinib as maintenance therapy in subjects with malignant pleural mesothelioma that has not progressed on at least four cycles of pemetrexed/platinum therapy. J Clin Oncol 325s 2014 Suppl Abstr TPS7611 2014.

[102] Study of FAK (Defactinib) and PD-1 (Pembrolizumab) Inhibition in Advanced Solid Malignancies (FAK-PD1) - https://clinicaltrials.gov/ct2/show/NCT02758587.

[103] Soria JC, Gan HK, Blagden SP, Plummer R, Arkenau HT, Ranson M, et al. A phase I, pharmacokinetic and pharmacodynamic study of GSK2256098, a focal adhesion kinase inhibitor, in patients with advanced solid tumors. Ann Oncol 2016;27:2268-74. doi:10.1093/annonc/mdw427.

[104] Felley-Bosco E, Stahel R. Hippo/YAP pathway for targeted therapy. TransI Lung Cancer Res 2014;3:75-83. doi:10.3978/j.issn.2218-6751.2014.02.03.

[105] Zhang W-Q, Dai Y-Y, Hsu P-C, Wang H, Cheng L, Yang Y-L, et al. Targeting YAP in malignant pleural mesothelioma. J Cell Mol Med 2017. doi:10.1111/jcmm.13182.

[106] Ganetespib With Platinum, in Patients With Malignant Pleural Mesothelioma https://clinicaltrials.gov/ct2/show/NCT01590160. 
[107] O'Brien MER, Gaafar RM, Popat S, Grossi F, Price A, Talbot DC, et al. Phase II study of first-line bortezomib and cisplatin in malignant pleural mesothelioma and prospective validation of progression free survival rate as a primary end-point for mesothelioma clinical trials (European Organisation for Research and Treatment of Cancer 08052). Eur J Cancer 2013;49:2815-22. doi:10.1016/j.ejca.2013.05.008.

[108] Ph 2/3 Study in Subjects With MPM w/Low ASS 1 Expression to Assess ADIPEG 20 With Pemetrexed and Cisplatin https://clinicaltrials.gov/ct2/show/NCT02709512.

[109] Judge S, Thomas P, Govindarajan V, Sharma P, Loggie B. Malignant Peritoneal Mesothelioma: Characterization of the Inflammatory Response in the Tumor Microenvironment. Ann Surg Oncol 2016;23:1496-500. doi:10.1245/s10434-0154965-6.

[110] Ujiie H, Kadota K, Nitadori J, Aerts JG, Woo KM, Sima CS, et al. The tumoral and stromal immune microenvironment in malignant pleural mesothelioma: A comprehensive analysis reveals prognostic immune markers. Oncoimmunology 2015;4. doi:10.1080/2162402X.2015.1009285.

[111] Yamada N, Oizumi S, Kikuchi E, Shinagawa N, Konishi-Sakakibara J, Ishimine A, et al. CD8+ tumor-infiltrating lymphocytes predict favorable prognosis in malignant pleural mesothelioma after resection. Cancer Immunol Immunother CII 2010;59:15439. doi:10.1007/s00262-010-0881-6.

[112] Anraku M, Cunningham KS, Yun Z, Tsao M-S, Zhang L, Keshavjee S, et al. Impact of tumor-infiltrating $T$ cells on survival in patients with malignant pleural mesothelioma. J Thorac Cardiovasc Surg 2008;135:823-9. doi:10.1016/j.jtcvs.2007.10.026.

[113] Cedrés S, Ponce-Aix S, Zugazagoitia J, Sansano I, Enguita A, Navarro-Mendivil A, et al. Analysis of expression of programmed cell death 1 ligand 1 (PD-L1) in malignant pleural mesothelioma (MPM). PloS One 2015;10:e0121071. doi:10.1371/journal.pone.0121071.

[114] Alley EW, Lopez J, Santoro A, Morosky A, Saraf S, Piperdi B, et al. Clinical safety and activity of pembrolizumab in patients with malignant pleural mesothelioma (KEYNOTE-028): preliminary results from a non-randomised, open-label, phase $1 \mathrm{~b}$ trial. Lancet Oncol 2017;18:623-30. doi:10.1016/S1470-2045(17)30169-9.

[115] Arpita Desai, Theodore Karrison, Buerkley Rose, Erika Pemberton, Bianca Hill, Christopher M. Straus, Yi-Hung Carol Tan, Tanguy Y. Phase II trial of pembrolizumab 
(P) in patients (pts) with previously-treated mesothelioma (MM). J Clin Oncol 2018;36:(suppl; abstr 8565).

[116] Quispel-Janssen J, Zago G, Schouten R, Buikhuisen W, Monkhorst K, Thunissen E, et al. OA13.01 A Phase II Study of Nivolumab in Malignant Pleural Mesothelioma (NivoMes): with Translational Research (TR) Biopies. J Thorac Oncol n.d.;12:S292-3. doi:10.1016/j.jtho.2016.11.300.

[117] Goto Y, Okada M, Kijima T, Aoe K, Kato T, Fujimoto N, et al. MA 19.01 A Phase II Study of Nivolumab: A Multicenter, Open-Label, Single Arm Study in Malignant Pleural Mesothelioma (MERIT). J Thorac Oncol 2017;12:S1883. doi:10.1016/j.jtho.2017.09.634.

[118] Hussein Hamad, Sumaira Shafi, Veronica Lenge De Rosen, Jun Zhang. A realworld experience of nivolumab in advanced malignant mesothelioma (MM). J Clin Oncol 2018;36:(suppl; abstr 8569).

[119] Hassan R, Thomas A, Patel MR, Nemunaitis JJ, Bennouna J, Powderly JD, et al. Avelumab (MSB0010718C; anti-PD-L1) in patients with advanced unresectable mesothelioma from the JAVELIN solid tumor phase Ib trial: Safety, clinical activity, and PD-L1 expression. J Clin Oncol 2016;34:8503-8503. doi:10.1200/JCO.2016.34.15_suppl.8503.

[120] Calabrò L, Morra A, Fonsatti E, Cutaia O, Amato G, Giannarelli D, et al. Tremelimumab for patients with chemotherapy-resistant advanced malignant mesothelioma: an open-label, single-arm, phase 2 trial. Lancet Oncol 2013;14:110411. doi:10.1016/S1470-2045(13)70381-4.

[121] Calabrò L, Morra A, Fonsatti E, Cutaia O, Fazio C, Annesi D, et al. Efficacy and safety of an intensified schedule of tremelimumab for chemotherapy-resistant malignant mesothelioma: an open-label, single-arm, phase 2 study. Lancet Respir Med 2015;3:301-9. doi:10.1016/S2213-2600(15)00092-2.

[122] Maio M, Scherpereel A, Calabrò L, Aerts J, Cedres Perez S, Bearz A, et al. Tremelimumab as second-line or third-line treatment in relapsed malignant mesothelioma (DETERMINE): a multicentre, international, randomised, double-blind, placebo-controlled phase $2 \mathrm{~b}$ trial. Lancet Oncol 2017. doi:10.1016/S14702045(17)30446-1.

[123] Zalcman G, Mazieres J, Greillier L, Lantuéjoul S, Dô P, Bylicki O, et al. LBA58_PR Second or 3rd line nivolumab (Nivo) versus nivo plus ipilimumab (Ipi) in malignant pleural mesothelioma (MPM) patients: Updated results of the IFCT-1501 
MAPS2 randomized phase 2 trial. Ann Oncol 2017;28.

[124] Disselhorst M, Harms E, Tinteren HV, Quispel-Janssen J, Monkhorst K, Burgers $\mathrm{S}$, et al. OA 02.02 Ipilimumab and Nivolumab in the Treatment of Recurrent Malignant Pleural Mesothelioma: A Phase II Study. J Thorac Oncol 2017;12:S1746. doi:10.1016/j.jtho.2017.09.329.

[125] Calabrò L, Morra A, Giannarelli D, Amato G, D'Incecco A, Covre A, et al. Tremelimumab combined with durvalumab in patients with mesothelioma (NIBITMESO-1): an open-label, non-randomised, phase 2 study. Lancet Respir Med 2018;6:451-60. doi:10.1016/S2213-2600(18)30151-6.

[126] Alley EW, Katz SI, Cengel KA, Simone CB. Immunotherapy and radiation therapy for malignant pleural mesothelioma. Transl Lung Cancer Res 2017;6:212-9. doi:10.21037/t|cr.2017.04.01.

[127] Wu L, Yun Z, Tagawa T, De la Maza L, Wu MO, Yu J, et al. Activation of CD1drestricted natural killer T cells can inhibit cancer cell proliferation during chemotherapy by promoting the immune responses in murine mesothelioma. Cancer Immunol Immunother CII 2014;63:1285-96. doi:10.1007/s00262-014-1597-9.

[128] Anna K. Nowak, Willem Joost Lesterhuis, Brett Gordon Maxwell Hughes, Chris Brown, Peey Sei Kok, Kenneth John O’Byrne, Tom John, Nick Pavlakis, Steven Chuan-Hao Kao, Sonia Yip, Deme John Karikios, Wei-Sen Lam, Ailsa Langford, Martin R. Stockler. DREAM: A phase II study of durvalumab with first line chemotherapy in mesothelioma-First results. J Clin Oncol 2018;36:(suppl; abstr 8503).

[129] A Randomised Phase II Open-label Study With a Phase lb Safety lead-in Cohort of ONCOS-102, an Immune-priming GM-CSF Coding Oncolytic Adenovirus, and Pemetrexed/Cisplatin in Patients With Unresectable Malignant Pleural Mesothelioma - https://clinicaltrials.gov/ct2/show/NCT02879669. 